\title{
Sojourner Reentry: A Grounded Elaboration of the Integrative Theory of Communication and Cross-Cultural Adaptation
}

\author{
Margaret Jane Pitts \\ University of Arizona
}

\begin{abstract}
Author Note
Margaret Jane Pitts is an Assistant Professor of Communication at the University of Arizona. A version of this paper was presented at the 2015 International Communication Association annual convention in San Juan, Puerto Rico. I would like to acknowledge Margaret Bellino for her assistance with transcription and data organization on this project.

Correspondence to: Margaret Jane Pitts, Department of Communication, University of Arizona, PO Box 210025, Tucson AZ, 85721-0025. Email: mjpitts@email.arizona.edu
\end{abstract}




\begin{abstract}
This paper offers grounded evidence in support of the elaboration of Kim's (2001) integrative theory of communication and cross-cultural adaptation to include sojourner reentry. Findings from 24 intensive interviews validate the heuristic value of ITCCA in the reentry context, but also reveal unique features that set reentry adaptation apart from cross-cultural adaptation. Key theoretical contributions include (1) a nuanced description of the role of reentry communication competence, (2) greater complexity of the roles and networks of interpersonal and mediated communication upon return, (3) an expansion to the environment domain to include "home environment,” and (4) a long-range perspective on the development of functional fitness, psychological health, and intercultural personhood. Implications for sojourner reentry training are addressed.
\end{abstract}

Keywords: reacculturation, reentry shock, identity, intercultural personhood, sojourner, study abroad, grounded theory 


\section{Sojourner Reentry: A Grounded Elaboration of the Integrative Theory of Communication and Cross-Cultural Adaptation}

There is no foreign land; it is the traveler only that is foreign. -Robert Lewis Stevenson

We are living at a time marked by human mobility and cultural diffusion. The ubiquity of cultural intersections makes them at once mundane and exceptional. On one hand, humans have the capacity to reach greater potential through transcendence of any singular culture to include multiple ways of knowing about and being in the world. On the other hand, we risk falling short of this potential by limiting our understanding of just how to incorporate our cross-cultural experiences into our daily lives. Our collective lack of knowledge about how to optimize the outcomes of sustained intercultural encounters means that for many people such experiences remain limiting. Yet, one of the positive outcomes of cultural interchange, such as study abroad, can be intercultural personhood (Kim, 2008). Intercultural personhood represents the psychic transformation a person undergoes as a result of experiencing and managing multiple communication and identity challenges when crossing cultures (Kim, 2008). Such a person is able to achieve a greater fit in our increasingly multicultural world (Gudykunst \& Kim, 1997; Kim, 2008). Meaningful and competent communication is at the center of this transformative process (Kim, 2001).

Of consequence here is not only the sheer number of people crossing borders for shortand long-term stays (see Institute of International Education [IIE], 2014) and for purposes of business, education, and leisure, among others, but also the fact that most sojourners return home (although see Onwumechili, Nwosu, Jackson, \& James-Hughes, 2003). Still, reentry has been given too little attention in the literature on sojourning and cross-cultural adaptation (Szkudlarek, 2010). We know almost nothing of the process of managing reentry beyond the initial return and there has been very little theorizing about, or empirical evidence of, the role of communication in 
reentry adjustment. A better understanding of sojourner reentry will contribute to broader theorizations of intercultural communication and international sojourning that extend beyond the encounters themselves just as the ramifications of the experiences do. Toward this end, and guided in part by a constructivist approach toward grounded theory (Charmaz, 2014), I sought to examine the communication and identity processes of sojourner reentry using Kim’s (2001, 2005) integrative theory of communication and cross-cultural adaptation (ITCCA) as a sensitizing framework. I conducted 24 intensive interviews in two waves (one at reentry and one six years later) to elicit sojourner reentry experiences over time. Based on these data, I propose an elaboration of ITCCA to better fit the reentry context and more fully capture the entirety of sojourner adjustment. This paper contributes at large to the scant literature on reentry adjustment and begins to extend and refine theory, from the ground up, about the communication and identity processes of reentry adaptation.

\section{Sojourner Reentry}

Sojourner reentry is an extension of the broader and complex phenomenon of intercultural adjustment (Martin \& Harrell, 2004). Reentry refers to the transitional process of returning and reintegrating into one’s home country after an extended period abroad. Returnees often experience a disruption of the social ties, roles, and routines developed in the host country and a loss of access to the lifestyle and material resources abroad to which the sojourner has become accustomed (Arthur, 2003). The reentry transition has been described as a grieving process wherein returnees mourn the loss of personal relationships, novel experiences, and a newly established way of life (Butcher, 2002). Thus, reentry is not merely a physical relocation, but also a social and psychological process of adjustment (Arthur, 2003). 
Many scholars have described the reentry period as more distressing than the initial cross-cultural adjustment (Martin, 1984; Walling et al., 2006). This is due in part to fundamental changes in the sojourners’ value structures while abroad (Uehara, 1986) and seems to be particularly challenging for students who do not want to return (Butcher, 2002) and for students who achieved a high level of integration in their host society (Cox, 2004). There are, however, a few studies that have not found significant reentry distress among returnees and argue that reentry difficulties might be the result of specific demographic variables and individual traits (e.g., age, sex, nationality, value difference) rather than being a generalized experience (Brabant, Palmer, \& Gramling, 1990; see also Pritchard, 2011).

Many of the difficulties experienced at reentry are similar to those of initial overseas adjustment, including discomfort and anxiety resulting from the loss of familiar cues, the need to integrate into a seemingly “different” cultural system, and the immediate pressures of culture learning and unlearning (Martin, 1984). Martin (1984) identified three reasons why difficulties at reentry are likely more intense than initial overseas adjustment. First, neither the returnees nor their social network anticipate reentry difficulties and are therefore unprepared. Second, it is likely that during the time abroad, both the sojourner and the home network/environment underwent some changes. Third, it is only through the reentry experience that the returnee is likely to become aware of the amount and significance of personal change and changes to the home environment. For example, returnees may struggle to resolve internal conflict created from the dissonance between old and new identities and between being uprooted from a culture they grew to appreciate and returned to a culture about which they may now hold new negative and critical feelings (Walling et al., 2006). 
Because sojourners have undergone complex changes that affect the whole self, returnees may experience their communication and relationships upon reentry in intercultural or intergroup terms (Smith, 1998) or as cultural strangers (Gudykunst \& Kim, 1997). A stranger is any person who is perceived as unknown and/or unfamiliar, especially when cultural differences are salient (Gudykunst \& Kim, 1997). The returnee may feel like a cultural stranger because she feels out of sync with the dominant cultural patterns. Moreover, members of the home culture may orient toward the returnee as a stranger because her behaviors seem unfamiliar, unpredictable, and difficult to explain, making them “strange.” For these reasons, communication upon reentry may well be cast in intercultural terms and mark an extended intercultural experience for the returnee.

During reentry, sojourners need to integrate their international experiences with their life back home (Smith, 1998). Indeed, it is only through the reentry transition that student sojourners begin to appreciate, incorporate, and enact the personal and cultural learning they experienced abroad (Arthur, 2003). One challenge returnees face is the need to redefine their identity and their relationships with family and friends who did not study abroad (Martin, 1986a, 1986b). For the returned sojourner who, in some cases, is trying to resolve both internal and external disconnects, communication may be the only channel. Communication is the driving force behind cultural adjustment (Kim, 2001; Rohrlich \& Martin, 1991; Smith, 1998). Pitts (2009), for example, found that everyday types of talk among sojourners facilitated their overseas adjustment by acting as a stress buffer and offering a means of collectively managing and aligning cultural expectations. Similarly, returnees use a variety of communication skills and practices to cope with the challenges of the return and as a way to resolve and renegotiate 
identities and relationships with varying degrees of success, effectiveness, and competence (Smith, 1998).

\section{Integrative Theory of Communication and Cross-Cultural Adaptation}

One theory of cultural adjustment that has emerged from the communication discipline is Kim’s (2001, 2005) integrative theory of communication and cross-cultural adaptation (ITCCA). Traditionally, ITCCA has been applied to the international context to account for sojourner adaptation (see Pitts, 2009) or applied domestically to account for acculturation among nondominant members to the dominant culture (see McKay-Semmler \& Kim, 2014). ITCCA may also provide insight into the transformative processes of reentry (Martin \& Harrell, 2004). ITCCA is based on a general systems framework that situates people as part of an open system of reciprocal environmental influence. ITCCA proposes that when the system is disrupted, as when sojourners return home, people are motivated to restore order to reduce stress. This is largely a communicative process. Sojourners use communication as an adaptive response to relieve stress, restore order, and recalibrate expectations and behaviors (Pitts, 2009). As the process is repeated over time, the sojourner experiences change that results in growth and intercultural identity transformation (Kim, 2005). The first boundary condition of ITCCA is (1) the sojourner, or stranger, is socialized primarily in one culture and then relocates to, or is embedded within, a different and unfamiliar culture. There is sufficient evidence to suggest that the international sojourn can result in such dramatic identity shifts that returning to the home culture can make it seem to the returnee and her social network as if she were a cultural stranger. That is, although the sojourner returns to the environment in which she was primarily socialized, ITCCA is still applicable to the reentry context because the returnee (stranger) must re-establish psychological health and functional fitness. The remaining boundary conditions hold equally 
well when "host” environment is replaced with "home” environment: (2) the stranger is dependent on the home environment for personal and social needs, and (3) the stranger engages in firsthand communication experiences within the home environment. Thus, returning sojourners who have experienced personal change abroad, who are dependent on their home networks to meet personal and social needs, and who engage directly in communication with members of the home environment meet the boundary conditions of ITCCA.

Kim’s (2001) original theory proposes five structural features that influence crosscultural adaptation: (1) sojourner predisposition (e.g., preparedness, adaptive personality), (2) host environment (e.g., receptiveness to strangers), (3) personal communication (e.g., communication competence within the host society), (4) social communication (e.g., engagement in host interpersonal and mediated communication), and (5) identity transformation (e.g., functional fitness, psychological health, and intercultural identity). For reentry adaptation, Martin and Harrell (2004) suggested the inclusion of home environment as a sixth domain.

The sojourner predisposition domain includes background and demographic variables that likely influence individual reentry experiences and re-adaptation (e.g., nationality, age, gender, religion, ethnicity, and socioeconomic status). It also includes personality attributes, such as openness, personality strength, and positivity (Kim, 2001), and preparedness for change (i.e., anticipating change and challenge during reentry, expectations for reentry, and prior reentry experiences; Martin \& Harrell, 2004). Together, sojourner predisposition constitutes adaptation potential (Kim, 2001).

In its original form, the "environment” structure in ITCCA refers only to the host country. It includes host receptivity (e.g., openness and willingness to allow strangers to integrate and participate socially in the host environment), host conformity pressure (e.g., degree 
to which host nationals expect and require strangers to assimilate to host country norms), and ethnic group strength (e.g., levels of prestige, presence, and power of sojourner's ethnic group in the host society). However, Martin and Harrell (2004) proposed that for reentry the environment domain should be conceived as having two dimensions: home and host culture. When applied to reentry, the host environment domain includes characteristics of the country where the student sojourned, level of sojourner integration, significance of cultural differences, and the amount of sojourner contact with home while abroad (Martin \& Harrell, 2004). The inclusion of the home environment in this domain refers primarily to the level of social support available to returning sojourners (Martin \& Harrell, 2004). Home environment also likely includes concepts from Kim’s (2001) original host environment domain, such as receptivity and conformity pressure.

The communication domain in ITCCA centers on four interrelated dimensions: host communication, ethnic communication, personal communication, and social communication. Each of these dimensions can be enacted interpersonally and/or through mass media. Traditionally, host communication refers to communicative engagement with members of the culture in which the student studies abroad, whereas ethnic communication refers to sojourner's communicative engagement with co-nationals. In general, ITCCA predicts that the more strangers communicate with the host culture, rather than co-nationals, the faster their cultural adaptation will be (Kim, 2001). Similar processes are at work upon reentry, although the location, sources, and channels of communication are reversed. For example, “host” communication in the reentry context refers to communicative engagement with home country members, whereas "co-national” communication refers to the social network the student developed during the sojourn. 
Personal communication traditionally has been tied to communication competence within the host society. It includes cognitive, affective, and operational competence. Cognitive components include sense-making abilities in the cultural context, knowledge of communication rules, ability to detect nonverbal codes, and so forth. Affective components relate to the emotional and motivational forces of adjustment, including the desire to meet self-expression and identity needs. Operational features include the technical skills of carrying out the tasks of daily life, but also communication creativity, resourcefulness, and synchrony (Kim, 2001). Synchrony emerges when interlocutors demonstrate coordination within interaction patterns including their form and timing, mutuality of attention, interest, and cooperation (Kim, 2012). Social communication largely involves the sojourner's engagement in interpersonal communication and mass media and includes contact with host country and home country networks. Social communication is about developing relationships with people in the host country and maintaining appropriate amounts of communication with co-nationals (Kim, 2001). Repositioned as a reentry feature, social communication might also include access to and availability of host country media and interpersonal networks, as well as access to a supportive network at home including people who have had similar international experiences.

The final reentry domain is re-adaptation outcomes (Martin \& Harrell, 2004). This domain, originally conceived by Kim (2001) as intercultural transformation, includes the gradual gain of psychological health and functional fitness and the development of intercultural personhood. Kim describes psychological health as the "taken-for-granted state of being” in which cognitive, affective, and operational tendencies are in sync with the host culture (p. 187). Functional fitness refers to the sojourner's ability to participate smoothly and comfortably in daily life activities. Finally, intercultural personhood emerges in the last phases of re-adaptation. 
The development of intercultural personhood is a synergetic process that enables the stranger to move beyond limits of a single culture to achieve a more transcendent notion of self. The emergent identity includes both an individualized sense of self (a clear notion of self and ability to see others as unique entities rather than as group members) and a universal sense of self (recognition of common humanity between people rather than a focus on difference).

\section{The Current Study}

Communication is at the center of the transformative and adaptive process of reentry, but only a handful of communication theories on sojourner reentry adjustment has been proposed (e.g., Martin 1984; Smith 1998), none of which have sufficiently describes the patterns of communication that move a returning sojourner from the position of cultural stranger to intercultural personhood. Moreover, existing research takes a limited scope of reentry, looking primarily at the immediate return. The perspective taken here is that reentry reflects the starting point (or at least a point along a much larger trajectory) of a deeper intercultural transformation and identity development that emerges over time and should be reflected in a communicationcentered theory of sojourner (re)adaptation. Although ITCCA primarily has been applied to host country cross-cultural adaptation, its versatility and open-system network should allow it to accommodate for varying routes toward reentry adaptation. Therefore, I used ITCCA as a sensitizing construct to guide this grounded theory approach ${ }^{i}$ toward the development of a more comprehensive theory of communication and sojourner (re)adaptation.

\section{Methods}

A grounded theory approach is data driven (Strauss \& Corbin, 1998). Theorists begin with a close examination of concrete empirical events and experiences and then organize data into increasingly abstract theoretical categories through a process of constant comparison and 
theoretical sampling until a grounded theory is constructed that encompasses participants' lived experiences (Charmaz, 2014). Constant comparison is a process of data-to-data comparison across and within data sets, then data-to-category and category-to-category comparisons, and sometimes, as in this study, emergent category-to-extant category comparisons (Charmaz, 2014; Glaser, 1978). Constant comparison allows the theorist to make analytic distinctions that assist in the development of the theoretic categories that form the foundation of a grounded theory. Theoretical sampling involves the pursuit of additional data (e.g., returning to raw data with new insight, collecting new data, and/or adapting instruments to pursue new questions) to illuminate and deepen theoretical categories as they emerge during iterative phases of data collection and analysis (Charmaz, 2014; Glaser, 1978).

\section{Data Collection}

To capture the communication and identity processes of reentry adjustment over time, I conducted two waves of intensive interviews with 24 participants (19 women, 5 men). The qualitative interview offers insight into participants' living worlds and the ways in which they make meaning of life experiences in the present moment and retrospectively (Rubin \& Rubin, 1995). Intensive interviews fit within the grounded theory approach as they facilitate the "openended, in-depth exploration of an area in which the interviewee has substantial experience” (Charmaz, 2014, p. 85). The first wave of data was collected in 2005 from a cohort of returning American students who studied abroad in Paris, France. This resulted in seven interviews with female participants. The second wave of data was collected in 2012 from members of the original Paris cohort (then in their sixth year post-return) and a new cohort of recent American returnees who studied abroad in either Nanjing, China, or Viña del Mar, Chile. This resulted in six wave-two Paris interviews (all female), eight Nanjing interviews (4 women, 4 men), and 
three Chile interviews ( 2 women, 1 man). Collecting data in two waves, once at reentry and again six years later, and from two cohorts of students (i.e., the 2005 and 2012 cohorts), offered insight into the immediate and long-range reentry experiences.

\section{Recruitment and Participants}

Wave-one interview data were collected in 2005 with IRB approval as part of a 15-month ethnography on student sojourning. For full methods regarding recruitment and data collection, see Pitts (2009). Wave-one data analyzed here included 7 interviews with young women immediately prior to or within three months of their reentry.

For wave two, I engaged in targeted recruitment and purposeful sampling after receiving university IRB approval. Qualitative inquiry often relies on a purposeful sample because of its ability to generate in-depth, experiential knowledge from a small but information-rich group of people who can best illuminate the phenomena under study and who are willing to share with the researcher in an articulate and meaningful way (Morse, 1991). Grounded theorists especially rely on a purposeful sample to obtain rich and focused data that enables them to deeply explore a specific phenomenon and construct theory from those data (Charmaz, 2014).

My previously established relationships with participants through ethnographic field work in Paris, an extended site visit to the Nanjing program in China, and teaching courses on applied intercultural communication helped me to establish the rapport necessary to gain participants. Rapport is a communication process that unfolds over time and can be described as perceptions of trust and sometimes intimacy that develop between researcher and participant (Pitts \& Miller-Day, 2007). The emergent and interactive nature of intensive interviewing can also facilitate rapport and may serve as a meaningful and cathartic experience for participants 
(Charmaz, 2002, 2014). A deep level of rapport was especially important in this study because of the emotional and highly personal experience of reentry.

For wave two, I recruited participants through direct invitation and network sampling. Direct invitations were sent by email and postal mail to all of the 2005 Paris cohort and by email to the 2012 Nanjing cohort. I also verbally invited then-current students who recently returned from a study abroad experience to participate and asked them to invite other members of their cohort. This resulted in 15 invited interviews (8 from Nanjing, 6 from Paris, and 1 from Viña del Mar) and 2 additional interviews from network sampling (both from Viña del Mar). Participant demographics reflect the national statistics of study abroad participants (i.e., predominately female, junior or senior class standing, and overwhelmingly Caucasian; IIE, 2014). Participation was voluntary. Participants were not compensated. All of the wave-two immediate reentry interviews were conducted within one year of students' return (3 months for the Nanjing students and 9 months for the Viña del Mar students). This time frame kept students close to the experience, but also gave them time to find meaning from the experience. Moreover, including different lengths of return time allowed different benchmarks of reentry adaptation to emerge.

\section{Interviews}

Grounded theorists simultaneously pursue two goals through intensive interviewing: attending to the participants (socially, emotionally, and professionally) and constructing theoretical analyses (Charmaz, 2014). I used a conversational interview style with a semistructured interview guide (see Rubin \& Rubin, 1995). This approach (a) allowed participants to shape the direction of the interview and pursue threads of discourse most meaningful to them (i.e., attending to participants), (b) created “interactive space” for the interviewer to immediately “pursue ideas and issues” that emerged during the interview (Charmaz, 2014, p. 85), and (c) 
offered necessary structure to maintain theoretical focus (e.g., constructing theoretical analyses). The flexible interview design offered opportunities for theoretical sampling both within individual interviews and across interviews over time.

Although the interview guides for immediate reentry at wave one and wave two differed slightly, both focused primarily on the social/behavioral, communicative, and affective experiences of reentry over time. Wave-two immediate reentry interviews began with orienting questions that encouraged participants to "tell me a little bit about yourself” (including demographic prompts) and “tell me about your study abroad” (including prompts for where, when, and how long). These questions established the tone and context for the interview. Students were then guided through the first content domain area, which consisted of general reentry questions designed to capture the experience at different time intervals (e.g., immediately prior to reentry, right at reentry, and in the months/years since initial reentry). Prompts included questions about daily activities, best/most challenging moments, and what it was like to be reunited with friends and family upon return. The next content domain area included communication and relationship questions at initial reentry and beyond. Driving questions asked "what have your relationships been like since your return" and "how would you describe your communication with friends and family since your return?” The final content domain area inquired about the effect of the study abroad experience over time and included identity questions (e.g., "tell me about what is the same/different about you and your life since you returned from your study abroad”) and questions about meaningfulness and integration of the experience into their lives to date. To capture benchmarks of time, participants were asked to identify the point in time during their reentry when they had specific experiences and for how long they felt a particular experience. Interviews concluded with a question designed to solicit 
additional insight from participants that did not emerge in the interview, "what else would you like to tell me about your reentry experience.” Wave-two retrospective interviews followed as above, but also included broad scope questions about participants' perceptions of the role that study abroad played in their life over the last six years and narrow scope questions about the transition from their initial reentry experiences to where they were at the time of the interview.

When possible, I interviewed returnees face-to-face in a comfortable university office or place of participant's choosing $(n=17)$. I conducted all seven of the wave-one Paris reentry interviews and ten of the wave-two immediate reentry interviews face-to-face. To accommodate student mobility post-sojourn, I also conducted seven wave-two interviews via Skype videoconferencing. This included one immediate reentry interview and all six of the retrospective interviews. All of the interviews were audio-recorded with consent and later transcribed. Interviews ranged between 40 and 120 minutes with most falling between 60 and 75 minutes. Participants were offered copies of their interview transcripts and invited to suggest edits or offer additional information. No participants provided feedback on their transcript.

\section{Data Analysis}

I used analytic procedures broadly outlined by grounded theorists (e.g., Charmaz, 2002, 2014; Glaser, 1978; Strauss \& Corbin, 1998). Grounded theory data analysis is an abductive process, moving inductively and deductively, but the general direction is "to move inductively upward from data to theoretical rendering” (Charmaz, 2002, p. 681). Constructivist grounded theory is a two-step process of initial or open coding followed by selective or focused coding (Charmaz, 2002, 2014). I used N-VIVO 9, a qualitative data analysis computer software system, to facilitate labeling, organizing, and code retrieval. 
I accomplished initial coding through line-by-line reading of each transcript. Within each line (or lines), I identified words, phrases, and passages that captured participants’ reentry experiences. Then, I assigned a short descriptive label (or code) to each utterance. When possible, I assigned in-vivo codes (e.g., used the participants' word or phrase) to connect the code directly to the participants’ lived experiences. During open coding I made no attempts to cluster data, but instead generated a list of meaningful free-standing codes that emerged directly from participants’ discourse $(n=501)$.

The second phase of coding involves sorting and synthesizing open codes to begin conceptualizing and theorizing about the data as a whole (Charmaz, 2002). During this phase, I reviewed the list of free codes and organized similar units of coded data into broader, thematic categories and subcategories that reflected students’ reentry experiences. Throughout this process, I used a constant comparison method to check for conceptual similarity and distinctiveness among and between codes and assessed the appropriateness of their placement within, and relationships to, thematic categories and subcategories (Charmaz, 2014; Strauss \& Corbin, 1998). As categories took shape during this phase, I began to consider the emergent data and categories through the lens of ITCCA as a sensitizing construct. This involves not merely “borrowing” ITCCA dimensions, but rather checking the fit of emergent data against existing categories and modifying those categories or adding new ones when necessary to represent the data. In this way, extant categories “earn” their way into an emerging grounded theory (Glaser, 1978). Moreover, by explicitly recognizing the role of sensitizing constructs in data analysis, the grounded theorist shows awareness about the extent to which such concepts influence the interpretations of data (Charmaz, 2002) and guards against forcing or selecting data to fit a priori categories (Glaser, 1978). Purposive application of a meaningful sensitizing construct allows the 
analyst to test the boundaries and usefulness of the construct in facilitating deeper theorization of the phenomenon under study (Charmaz, 2002).

Finally, I used Lincoln and Guba’s (1985) benchmarks for establishing trustworthiness in qualitative research including transferability, confirmability, dependability, and credibility. Transferability (e.g., likelihood that findings from this study might be extended to another similar case) was enhanced in this study through empirically derived data, abductive reasoning, and theoretical linkage. Confirmability refers to the extent to which outsiders would be able to reach similar conclusions from the data set. I sought to ensure confirmability through meticulous data management, detailed articulation of my analytic methods, and by assigning open codes that reflected participants' expressions (rather than my interpretations). Dependability (e.g., whether there is demonstrable consistency between researcher and participants) was achieved in part through development of strong rapport as well as offering participants opportunities to review and edit transcripts. Credibility refers to the extent to which interpretations are established as plausible truths. To demonstrate plausible truth, I grounded my theoretical analysis to emergent empirical data, used a constant-comparative method to ascertain fit between code and category, and demonstrated consistencies within the data and broader scholarly discourse by linking the data to established theory.

\section{Findings}

Through the emergent and abductive design of grounded theory methods, I uncovered and pursued unique thematic categories that gave form to the processes and patterns of sojourner communication and reentry adaptation. Once revealed, categories, and their generative themes, were subject to a process of constant comparison using ITCCA as a sensitizing, but not doctrinaire, construct (Glaser, 1978). The result was 26 emergent categories that clustered into 
10 domains; nine of the original ITCCA domains plus an additional domain. The emergent findings are presented within the broader domains below.

\section{Pre-reentry Context and Characteristics}

Five novel themes emerged to create a unique pre-reentry context. These features appear to set student sojourner reentry adaptation apart from initial cross-cultural adaptation and likely contributed to reentry difficulties.

Pre-reentry stress. First, for many students the weeks leading up to their return were consumed with final examinations and ending coursework. Students described academic pressures surrounding pre-reentry as chaotic and stressful resulting in little time to reflect upon their sojourn and no time to think about reentry.

Intensifying the abroad experience. Second, students reported that as they became aware of their imminent departure, they began to feel a sense of desperation to maximize their experiences abroad by revisiting favorite places, engaging in favorite activities, and completing their study abroad "bucket list.” Thus, immediately prior to reentry, students spent the majority of their time intensifying their sense of presence and permanence abroad rather than preparing for their return.

Denial and grief. Students’ resurgence of commitment to their experience abroad led to the third theme: a sense of denial and grief that the experience was ending. One student described her pre-reentry experiences as “proactive mourning” that the experience was ending.

Unaware of change. Fourth, students demonstrated a lack of awareness of personal change. Students described having a vague sense of personal change, but they were unable to pinpoint the direction or magnitude of that change. Their lack of self-awareness about personal 
change resulted in difficulties upon return when many were confronted with a conflict between their former and new identities and feeling disconnected from society.

Transition time. The fifth pre-reentry theme emerged as a positive experience among returnees that appeared to buffer some reentry stress. Transition time played an important role in student reentry. Students who delayed reentry either through additional travel at home or abroad at the conclusion of the academic session or by returning home to participate in a life event (e.g., wedding or holiday) seemed to be buffered against the full effect of reentry shock. Extended travel and life events offered a sort of "limbo" state wherein students were in between the experience of their sojourn and the reality of their return. In a smaller way, students also talked about the importance of the long flight home as a time to reflectively savor their experiences abroad, but also to prepare mentally for the return. Thus, transition time offered students the opportunity to reflect upon their experiences abroad and prepare for their reentry, whereas transition travel gave students the chance to re-engage their adaptive personality and skills.

\section{Environment}

Participant discourse centered on issues related to authenticity and fit at home and abroad. Participants described feeling caught between two worlds: the host environment where they felt "at home” and the home environment where they no longer "fit in.” Therefore, within the broader "environment" domain, two distinct categories emerged each with their own themes: "host environment” and "home environment."

\section{Host environment.}

Authentic self abroad. Participants reported feeling welcome, well-received, and genuinely accepted for who they were in their host culture. Many participants reported feeling appreciated for their “authentic” self only in the host country (e.g., “I’ve never felt happier. I’ve 
never felt more in place”). This was in contrast to the experience reported by another participant. When asked "where or when do you feel most like you," she replied "not here [USA], definitely not here.” One participant described her experience abroad as the chance to meet "the inner me that I needed to meet.” Participants experienced difficulties with reentry because they lost that sense of authenticity and connection upon return. One participant explained that she "loved who [she] was when [she] was abroad," but upon return felt as though she “couldn't be who [she] was there, here."

Culturally immersed. Participants described having "bonded” with the culture, being completely “immersed” in the culture and language, and being “over the moon about it.” A returnee from Chile lamented that it was difficult to leave her host family and host country behind because she felt entirely immersed in their culture. One participant explained that even six years after her return she still struggled with feeling more connected to France than the U.S.; she still "yearn[ed] to be an expat." Several participants also described feeling so culturally immersed in their host country that it felt like home to them; “I just didn’t want to let go of Paris; I felt like I had built a home there.”

\section{Home environment.}

Different from other Americans. Upon return, sojourners perceived themselves to be different from other Americans as a result of their international experience. In particular, participants expressed that their mindset had changed and was fundamentally different than that of the dominant U.S. culture. A common thread among returnees was a feeling that they just “didn’t resonate” with this “reality” or, as one participant explained, “I know who I am, but in this society I don’t really know how I fit in.” 
Dislike and disconnect from USA. Participants also expressed strong feelings of dislike toward and disconnect from the mainstream U.S. Returnees reported feeling highly critical of the U.S. with regard to materialism and excess. One participant described feeling both nervous and annoyed about his new sense that people in the U.S. are "cheeky," "fake," and "phony." Others reported becoming “judgmental,” “critical,” and “cynical” about the U.S. since their return. Returnees described feeling anger toward the U.S. and its cultural values: “I don’t want to hate this country but I kind of feel like I do and that's not ok with me.”

Difficulty with routines and expectations. Participants also described finding it difficult to fit into the routines and expectations already set for them at home. Returnees explained that they felt expected to resume life as usual and return to American values and ways of doing things. This resulted in feelings of “confinement” and “claustrophobia” for returnees, many of whom experienced personal independence for the first time in their lives. Participants used terms such as “super-constrained,” “entering jail,” “a mental prison,” and “being forced back into this university bubble” to describe feelings of conformity pressure at reentry.

\section{Reentry Communication}

Communication upon reentry posed significant challenges to returned sojourners, but also opened opportunities to facilitate adaptation. Students found the affective aspects of reentry communication difficult and interpersonal communication with their home network strained. However, participants also described their communication with co-sojourners and international others rewarding and meaningful. Participants used both interpersonal and mediated channels to communicate with their home and abroad networks.

Home network interpersonal communication. Interpersonal communication challenges with the home network accounted for much of the immediate (within one year) experiences of 
reentry shock. Participants’ perceptions of cultural disconnect were exacerbated by difficulties communicating important and personal experiences in an effective manner. Returnees perceived a serious lack of support and understanding from their home network and at the same time were frustrated at their own inabilities to communicate meaningfully about their experience. Four interpersonal communication challenges emerged as themes that impeded reentry adaptation.

Need to share. Participants described a driving compulsion to talk ad infinitum about their study abroad experience upon return (e.g., “I couldn’t stop talking about France all the time”). The short- and long-term returnees all expressed that in the weeks immediately following the sojourn their identity seemed to be defined by their study abroad experience and they "just had to tell everybody.” As one participant explained, “I felt like I needed to just talk about China to just make up for the fact that I wasn't there.” However, within three to four months of return, participants recognized that their constant need to relive their experience abroad verbally likely “irritated,” “annoyed,” “frustrated,” and “overloaded” their home network. They attempted to curtail their sharing and "talk about it only when it's relevant” or stop “oversharing because it doesn’t benefit anyone.” Unfortunately, this led to numerous unfulfilling encounters wherein returnees felt constrained in their sharing.

Difficult to explain. The need to share was overshadowed by the impossibility of "put[ting] the experience into words.” One participant put into focus the distinction between cognitive and affective (reentry) communication competence in reporting on her difficult reentry: I know how to speak English, but there aren’t words that exist, to my knowledge, that can capture what it is I am trying to say. Like even the word “love” is so small it doesn't, I can’t be like "I loved everything” that to me just irritated me, cuz it was bigger than that. Students felt their experience was somehow "lost in translation" and so difficult to express that 
they often resorted to describing the whole experience, inadequately, in one or a few words. This too resulted in unfulfilling communication encounters.

Lack of support. Returnees were disappointed in the level of sincere interest conveyed by their home network and "irritated" at the kinds of questions people asked about their experiences abroad. To participants, many questions were "simple” and centered on "stereotypes” or the "weird stuff” about the host country. The home network always seemed to "expect an answer” (especially about how "great" the experience was), but had no interest in hearing a genuine response. Upon returning from Chile, one participant described this feeling as,“'Yeay, I’m back in the U.S., [I'm] gonna share my ideas, I'm this whole new person, I'm so amped!' And when people aren’t as receptive to that, it’s hard, like it really hurts, actually.” Returnees generally felt that much of their home network communicated in ways that devalued or underappreciated the gravity of returnees’ full experiences.

Unable to relate to others. Returnees also spoke about realizing that “people don't really know a part of you all of a sudden.” Participants found it difficult to relate to some members of their home network because they had not had the same kind of "life-changing experience." One recent returnee described her experience returning from Chile:

Any life-changing, transformative experience for yourself is so difficult to explain to somebody. I think it’s a difference between sympathy and empathy, when you're with somebody they can understand it and when you're not, it’s like you can understand the concepts but you'll never have what I had. And for that, I was bitter and I was angry and I changed a lot in my relationships when I got back because my mentality was different and I couldn’t, I can’t explain how I'm different, I just am.

In several cases, this experience gap caused some tension within the home network because 
returnees were unable to describe their experience adequately and friends and family were not able to understand or appreciate how the student might have changed. Regardless, there was agreement that “there are certain friends that I don’t share my abroad experience with because they didn’t go abroad and they kind of-they’re irritated by it, they don't want to hear about it because they have no idea what it’s like.”

Home network mediated communication while abroad. In general, students appeared to return to their previously established patterns of mediated communication within the U.S. Some students talked about catching up on news or television they missed while abroad, but home network mediated communication did not seem to play a significant role in the reentry experience. However, the level of contact and connectivity through communication technologies between sojourners and their home network while abroad did appear to influence the reentry experience positively.

Students who studied abroad recently had many more opportunities to maintain relationships with their home network using new media and communication technologies than those who studied abroad six years prior. The 2005 Paris program participants relied largely on sending mass emails to their home network while abroad, but even this level of connectivity seemed to help them maintain their relationships at home and ease their return. For instance, one Paris participant described how maintaining open lines of communication helped her reentry:

I had been sending emails the whole time I was there. I was sharing everything with my friends from home. So the ones who read them all, they knew what I had gone through and they were either really jealous of me, or they were really happy for me, and-but mostly they were just excited I was home again. 
There was a sense that talking to friends and family "normally, throughout the whole thing" made reentry encounters with others less uncomfortable. China participants in particular talked about "tricking the system” to use Facebook to maintain their relationships at home, reporting that "Facebook helps immensely" to stay in touch with "base relationships." One participant described how posting frequent status updates on Facebook “did help me get better integrated” because members of her home network read and commented on them. For her, social media "was a really big thing that helped me get back into it because I knew that people actually wanted me to come back.”

International network interpersonal communication. Although the home network was a continuous source of antagonism for returnees, the international network was a source of strength. Participants managed reentry difficulties by maintaining communication with cosojourners, others who had similar international experiences, and personal relationships developed abroad.

Support from returnees. Returnees found solidarity and relief by seeking out and sharing their experiences with others who had similar experiences. Especially in the first three months of reentry, returnees tended to contact members of their study abroad group to reminisce and "share an experience with someone you shared the experience with.” For one of the Chile participants, her international network proved a pivotal source of support during her return:

Having the people to go back to and [say] "I am not okay,” ya know, “can we meet up and talk?” ... I feel like Sonia and I met up every couple days-went and got ice cream and just talked, cuz we just had to. There was no one else I could share my feelings with than someone that understood exactly what I was going through because they were going through the exact same thing. 
The international network offered opportunities for participants to engage in supportive, meaningful, and fulfilling communication that was lacking from much of their home network.

Maintain host communication. Participants also expected to maintain communication with host family and friends for personal and professional reasons. For some, the expectation that “this [relationship] is gonna continue for the rest of my life and I'm gonna keep these relationships forever” eased the difficulty of saying good-bye to close relationships developed abroad. Recent returnees, particularly those with host families, were highly motivated to maintain communication with their social network abroad. Although long-term returnees still spoke about the past importance of maintaining communication with members of the host society, they also described a waning of that motivation. By the six-year benchmark, the desire to maintain an interpersonal relationship with host contacts transitioned into a broader interest in developing relationships with people who shared similar international experiences and/or worldviews.

\section{International network mediated communication.}

Mediated social network. Recent returnees described making efforts to develop and maintain an on-line social network among other returnees and with members of their host society. Returnees were also keen to use social networking and mass media to keep up with events happening in their host country. Maintaining connectivity through communication technologies appeared to serve as a buffer against some reentry stress by allowing participants to stay engaged in the lives of their study abroad network and keep abreast of what was happening in their host country.

News and entertainment. A second way in which the abroad network used mediated communication as part of their reentry adjustment was by seeking news sources and 
entertainment media from their host culture. This allowed returnees to continue to live abroad vicariously. One returnee explained:

I read everything and anything I can about China now. I have four different apps on my phone to just keep up with everything that's going- to maintain that connection. It's important ... That was your life for a certain amount of time. So, that's why I read the news about China all the time.

Continuous access to the Internet and social media created a novel influence on sojourner readjustment by allowing them to maintain and extend their newly established social networks well into reentry.

\section{Intercultural Transformation}

Returnees’ newly acquired cultural identity was the most salient part of their identity, the part they wished others to recognize and the part that they were trying to reconcile as they transitioned to life at home. Sojourners described a slow process of reentry adjustment that appeared to proceed in phases. First, participants experienced renewed functional fitness, then a return to psychological health, and finally the emergence of a new, integrated identity.

\section{Functional fitness.}

Feeling overwhelmed. Students appeared to have short-term difficulties reestablishing functional fitness at home, especially with regard to cognitive aspects of communication competence. Students noted their discomfort and shock at being "surrounded by a bunch of people speaking English.” Students described feeling over-stimulated and unable to focus on conversations finding them loud, obnoxious, and superficial. Participants described feeling dazed when confronted with the abundance of choices available to them in almost every aspect of their 
consumer lives. Students also described feeling out of sync with what was going on around them and unable to function as they normally would.

Acceptance. The reestablishment of functional fitness was primarily a process of letting go of their newly developed cultural (and mental) patterns and accepting the cultural reality of home. For example, one participant realized he had returned to "normal” when "the desire to 'live in Chinese' was diminished” and when his "annoyance” at "certain American customs was sort of eroded” and instead became “expected.” In other words, once he stopped trying to do things the Chinese way, he was better able to function in the U.S.

\section{Psychological health.}

Negative emotions. Participants described immediate reentry with a host of negative emotions reflective of their strained psychological health upon return. Overwhelmingly, students' descriptions of their reentry experiences, both at the time of reentry and several years later, were characterized by intense negative emotions (e.g., “wanting to slit my wrists”). The retrospective data revealed that even though returnees do psychologically adjust over time, even six years later participants recalled the reentry experience in emotionally laden ways. Many students described the reentry experience as a time of mourning or loss ("it was like a friend died”). Although a few students described the experience as a mixed response of excitement and anxiety, most students described it negatively with descriptors ranging from awkward, sad, hectic, and boring, to the more extreme, toxic, tragic, suicidal, anger, and dread.

Subtle shifts to "normal.” For most, the return to psychological health was a subtle process that occurred over time. Participants realized that at some point they were no longer ruminating and talking about their host country all the time: “everything kind of just faded back to normal.” Others described it as being like waking up: “I woke up one day and I was like 'I feel 
like myself again’ ... I feel good, I love life again, I’m excited, I don’t agree with a lot of things, but I'm ok with the person that I am.” Participant discourse also revealed some consistent benchmarks with regard to the passage of time and psychological readjustment. Participants reported that the two-week benchmark foretold the end of the most painful emotional aspects of the return (participants were no longer crying all the time and had fully recovered from jetlag). Another benchmark was between three and four months when participants noticed they were no longer fighting the urge to compare everything to their abroad experience. After four months, benchmarks stretched into academic years or life events (such as graduating, starting or completing a degree, or beginning a career). At six years post-sojourn, the Paris participants reported that they were no longer negatively affected by reentry and tended to see the entire experience as a positive, transformative one. Indeed, most of the Paris participants remarked that they had completed their reentry transformation and, with few exceptions, had learned how to live with the study abroad experience behind them. Moreover, they able to pinpoint ways in which it positively influenced the more meaningful elements of their lives.

Positive reframing. One indication of psychological health was participants’ eventual ability to move beyond their negative emotions toward positive reframing. One student explained, “coming back to the U.S. is an adjustment and so it was continuing growth.” This finding was more prominent among long-term returnees, such as the Paris participant quoted below, than at immediate reentry, giving indication of the importance of time for readjustment. I kind of left a part of myself there, that I feel like I'll (laughing) never get back because, you know, you kind of feel a little incomplete, you'll always miss it. Kind of want to be two places at once, but...That's alright...It's unfortunate but at the same time it's a gift 
right? That you love more than one place? I think it would be a little limiting if you only really felt at home in one place.

In sum, although many returnees described immediate reentry as an intensively negative experience, over time returnees were able to positively reframe reentry and even point to it as an opportunity for continued growth.

Intercultural Personhood. Participants at all stages of reentry demonstrated some movement toward intercultural personhood, but this was especially evident among long-term returnees. Those with a longer reentry experience had time to learn how to incorporate the experience into their lives at home, whereas the more recent returnees were still trying to live in the moment of their study abroad. Recent returnees struggled with how to make the experience meaningful in their lives moving forward. Over time, however, the transition toward intercultural personhood was evident in participants’ narratives post-return as they described achieving both an individualized and universal sense of self.

Individualized self - integrated identity. Participants described developing an integrated identity that included awareness that the study abroad is part but not the totality of their personhood (e.g., “I don’t belong [in Paris] anymore, but it’s a part of who I am”). One student described coming to terms with her integrated identity after returning to Paris years after her study abroad:

Your study abroad experience isn't visiting those places it’s really, it’s the experience you know?...I think that's what's special about it, it's a feeling and an experience rather than a memory and a place. And so that's what's so cool, you know, you can take it with you and use it in your life going forward.

Contrast that with a student who returned from Chili only nine months prior: 
When you're there, it's reality. And, when you're here, it's a memory. Every single thing that had built up to it was so perfect in moments and now they're all memories. And it was tragic. It was like a friend died. That's how I compare it. I mean, like I miss something so much and the memory will always be with me but it's never the same. The study abroad became "a feeling and an experience rather than a memory and a place” for those with longer reentry time compared to “when you're there, it’s reality... here, it’s a memory” for those still managing early reentry. Participants with longer reentry experience acknowledged that over time the study abroad was no longer the most salient and encompassing aspect their identity, but that it continued to shape who they were. For example, one participant explained that six years later, “I don’t think that the first thing I would, say is 'oh I speak French and I studied abroad,' but it's definitely in there and it affects-I know it affects the way that I see the world and interact with people.”

Universal self - connecting with humanity. All of the long-term returnees and several recent returnees described how they integrated their study abroad experiences into their lives through international and humanitarian efforts that ranged from volunteer medical work or teaching in rural areas of developing countries, to Peace Corps and working with U.S. organizations to assist immigrants. One participant realized upon return that she “just didn’t want to go back to this,” referring to her previous U.S. lifestyle. She explained, “working with immigrants was a really good way to sort of keep my eyes to the outside world.” For another participant, his expanded sense of self resulted in the desire pursue international law to help people who "are not part of my community, but are still human beings, and who need help.” The development of a universal sense of self included expressions of cultural empathy, connections with the international community, and a desire to do something important globally. 


\section{Discussion}

The purpose of this analysis was to build toward a more comprehensive and grounded theory of communication and sojourner adaptation by including sojourner reentry experiences. When considered vis-á-vis ITCCA, the findings revealed several unique contextual and communicative themes that distinguish reentry adaptation from initial cross-cultural adaptation. Sojourners are not, in fact, relocating to a completely new, completely strange environment, but one with which they already have some baseline similarity. This basic feature sets reentry adaptation processes on a similar but somewhat unique trajectory from initial cross-cultural adaptation. Thus, the unique themes that emerged through this grounded analysis provide the opportunity to expand the scope of ITTCA to include reentry adaptation as part of the overall adaptation process. The following discussion articulates areas of theoretical fit and expansion.

Pre-reentry Context and Characteristics. One elaboration of the ITCCA structural model is to include contextual features unique to pre-reentry. Themes that emerged with regard to pre-reentry (i.e., academic stress, intensification of the abroad experience, denial/grief, unawareness of change, and opportunities for transition time) suggest there is a need to consider a wider constellation of contexts surrounding pre-reentry that uniquely influence sojourners’ capacity for a smooth(er) reentry. The predispositional characteristics built prior to reentry will affect the rate and extent to which sojourners will readapt to home. For many, the final days of the sojourn are intensely (and negatively) felt making the pre-reentry context somewhat different from pre-departure. For example, stress is heightened for students during pre-reentry who are completing final exams while simultaneously coping with the grief and anxiety of leaving a host culture, social network, and life experience they are uncertain they will ever recapture. The overall negative valence of pre-reentry experiences set it apart from the more positively valenced 
(“honeymoon”) pre-departure experiences and expectations often described (see Pitts, 2009).

This is not to say the pre-reentry experience is entirely negative. Indeed, a handful of participants described the time as one of anxious-excitement and bitter-sweet (see also Kartoshkina, 2015). Nor did it mean that nobody was happy to return home. Rather, these data suggest that the prevalence of negative emotions and lack of preparation surrounding reentry are likely different from the positive emotions and preparation that surround pre-departure and influence sojourner reentry predisposition, and thus reentry adaptation, differently.

Environment. Themes distinctly related to host culture environment (i.e., authentic self abroad and cultural immersion) and to home culture environment (i.e., different from other Americans, difficulty with routines/expectations, and dislike/disconnect from USA) emerged in clear support of Martin and Harrell's (2004) position that the ITCCA model be expanded to include both environmental domains. Whereas ITCCA places focal attention on the role of the host society in shaping sojourners' cross-cultural adaptation experiences abroad, consideration of only one environmental domain at reentry glosses over the unique experience of returning to a formerly familiar environment, but as a changed individual. For example, although sojourners likely feel some disconnect and cultural strain when they first arrive overseas, to some extent it is anticipated because they are, indeed, strangers. However, for returnees the feeling of cultural disconnect may be exacerbated because "home” likely represents a taken for granted place where returnees expect to fit in and do not expect to be received as a cultural stranger. Thematic findings related to feeling more authentic abroad and different from (and distain toward) other Americans at home give grounded evidence for the inclusion of both domains as separate and influential categories. 
Incorporating host and home culture environmental dimensions in the reentry context offers deeper insight into the complex relationship between the two as they impact upon sojourner reentry adjustment. Understanding the cultural dimensions of the host environment (e.g., receptiveness, in-group strength, and conformity pressure from Kim's model) can shed light on the sojourner's potential for and magnitude of cultural change abroad. That is, the environment level features of the host country will affect individual level cultural change. Simultaneous knowledge of the home environment dimensions can shed light on how open the home environment will be toward receiving returnees who may now appear to be "strangers.” The extent to which returning sojourners are accepted back into the home environment, are able to express their new sense of self comfortably, and are able to develop supportive networks with others who have shared similar experiences are important features of the home environment that influence adaptation potential. Thus, to maximize ITCCA's potential in the reentry context, both the host and the home environment domains should be included because they give insight into the sojourner's potential for change abroad and potential for adaptation at home.

Reentry communication. Consistent with ITCCA, themes that emerged from this study demonstrate that communication is also a significant part of the reentry adaptation experience. For example, constrained interpersonal communication with the home network upon reentry hinders initial reentry adaptation much like limited or constrained communication with the host culture hinders cross-cultural adaptation. On the other hand, interpersonal communication with the international network upon return provides the sojourner with a necessary sense of support and validation of their experiences much like co-national communication abroad (Pitts, 2009).

There were also some unique themes that emerged with regard to communication patterns at reentry that differentiate it from cross-cultural adaptation. For example, returnees are largely 
concerned with reestablishing connection and working toward homeostasis in a formerly familiar environment rather than creating new connections and adjusting to an unfamiliar cultural and linguistic environment. Moreover, as a result of sojourners' changed communication patterns (Hsu, 2010), they may discover the need to summon and refine communication skills to better meet their own needs and others' expectations. This process likely involves “unlearning” of some of the communication patterns developed abroad and (re)accommodating to the dominant patterns at home (see Hsu, 2010).

Also, although cross-cultural and reentry adjustment both appear to be a function of the development of social and personal communication competence in their respective environments, the competence needs differ. Because sojourners return to an environment where their baseline communication practices are already established, their communication competence requirements upon return likely shift away from the cognitive and operational competence needs that might take precedence abroad and redirect more intensely on affective competence. Affective processes appear to be particularly problematic for returnees as they attempt to communicate about their experiences in a meaningful way that meets the needs for selfexpression and aesthetic coordination, but also meets listener's needs and expectations. The heightened salience and necessity of affective communication competence upon return may help to explain why communication during reentry has always been found to be strained (e.g., Martin, 1986b). In comparison, cognitive processes that involve basic sense-making are less problematic upon return especially compared to their importance abroad. However, findings from this study indicate that even cognitive communication competence can be difficult at reentry in part because the returnee feels out of sync communicatively and inundated by messages. Operational 
processes are also likely to pose some difficulty, especially as returnees learn how to talk about their experiences abroad effectively for professional or academic purposes.

With regard to media communication, returnees may be able to escape some reentry stress and also maintain a sense of connection to their host culture by engaging in host culture media upon return. Sojourners may also find comfort in returning to familiar news and entertainment media from their home culture. However, some of the unique themes that emerged from this study suggest further elaboration of ITCCA to include a more nuanced role of media in reentry adjustment (i.e., establishing a mediated social network for support while abroad and again upon return, and seeking host culture news and entertainment media upon return). In addition to the traditional forms of media, returning students make significant use of new media technologies. Social media and social networking sites allowed users to bridge space and time and connect rapidly (and synchronously) to a dense personal network. Social media are an important expansion to Kim's original model because of their ubiquitous use at all stages of the sojourn from pre-departure throughout years following reentry. Although sojourners appear to rely on social media as a means to access the types of support they need during different phases of the sojourn, social media operate differently for the home network and the international network. While abroad, sojourners depend on social media to connect with their home network. This provides students abroad with a sense of connection to home and support that ultimately helps establish a smoother reentry transition. At reentry, however, returnees turn to social media to maintain their newly developed international relationships as well as to seek support from others who have shared experiences. Social networking may extend the potential effects of a sojourn by allowing returnees to easily maintain a connection with co-sojourners and members 
of their host country for years beyond reentry. This has important implications for more widespread and sustained intercultural personhood development.

Intercultural transformation. Finally, themes related to processes of social and psychological adaptation also emerged and point to the importance of examining adjustment beyond initial reentry. Functional fitness would not normally pose a problem for cultural ingroup members. Yet, short-term sojourners appear to experience difficulties initially reestablishing functional fitness upon return (e.g., feeling overwhelmed, over-stimulated, and out of sync culturally and communicatively). Still, compared to other intercultural transformations, returnees were able to re-establish functional fitness at home relatively quickly likely because of their deeply embedded home-culture knowledge. Thus, functional fitness appears to be the first of the three adaptive "transformations” returnees were able to make.

Compared to functional fitness, psychological health for returnees posed a much deeper and persistent problem. Many sojourners experienced powerful negative emotions at the time of reentry that were both unexpected and difficult to resolve. For example, the dissonance between who sojourners felt they were upon return and the ways in which they were received by their home network caused significant and enduring disruption to their psychological health. Within about three or four months of reentry, however, returnees experienced their first subtle shift to “normal” marked by no longer feeling desperate to return to the host society. A second phase of re-establishing psychological health occurred for longer-term returnees-positive reframing of the difficult experiences as growthful ones and appreciating the difficulties as part of the entirety of their intercultural experience. These findings point to the necessity of taking a long-range perspective on the reestablishment of psychological health among returning sojourners to capture the subtle phases of adjustment and transformation over time. 
The third intercultural transformation, intercultural personhood, emerges as a result of frequent meaningful interactions with cultural others and through meeting and overcoming multiple intercultural challenges (Kim, 2001). The developmental nature of intercultural personhood necessitates a long-range perspective. Intercultural personhood is likely accelerated, and quite possibly only genuinely achieved, for those sojourners who have the opportunity to return home (or relocate) in order to recognize and resolve identity changes in a positive manner and enact the newly emerged identity in a meaningful way. Returning sojourners expressed both individual and universal layers of intercultural personhood in the form of an integrated identity achieved through resolving identity conflict post-sojourn and feelings of a deeper connection with humanity through experiencing life as a cultural stranger. Thus, by extending ITCCA beyond initial reentry, scholars and practitioners can better understand the more nuanced development of intercultural personhood over time.

A final note with regard to the overall findings, because of its open-system framework, the structural features of ITCCA are interconnected and not easily contained in individual domains. This casts some amount of fuzziness on the findings hitherto presented separately, but in reality are mutually implicated. For example, low perceptions of receptivity in the home environment may be partially attributed to poor communication with the home network at reentry—especially perceived lack of support, lack of genuine interest, and lack of understanding or valuing the sojourner's experience. Moreover, individual responses (e.g., feeling disconnected) to environment level dimensions (e.g., lack of home receptivity) must also be considered with obstacles to psychological health and functional fitness.

\section{Theoretical Contributions}


This paper points to several potential theoretical contributions to the field of intercultural communication. First, it proposes a grounded theoretical elaboration of Kim's (2001) integrative theory of communication and cross-cultural adaptation that includes sojourner reentry adaptation. Second, the exclusive focus on the reentry phase brings awareness and nuance to the unique context and challenges of reentry adaptation positioned against similar experiences of cross-cultural adaptation. Third, it centralizes the role of communication in this transformative experience by (1) drawing attention to the importance of cognitive, affective, and operational communication competence in the reentry context, (2) identifying interpersonal communication challenges that hinder adaptation as well as communication practices that facilitate adaptation, and (3) expanding the mediated communication dimension to include social media and social networks upon return. Fourth, it considers reentry adjustment beyond the initial return highlighting the importance of time in the development of functional fitness, psychological health, and, ultimately, intercultural personhood.

\section{Practical Implications}

The findings from this study have implications for reentry training that could change the way study abroad programs are developed and implemented. U.S. higher education has done a good job at promoting and increasing overall study abroad participation among U.S. students (IIE, 2014). We must now position returnees in ways that maximize the benefits of their international experiences by helping them to find meaningful ways to enact their emergent intercultural identities and to integrate their cultural experiences into their lives at home and society in general (Pritchard, 2011).

The first step toward increasing long-term positive outcomes of the international sojourn is to equip students with what Arthur (2003) termed anticipatory coping strategies for reentry 
adjustment. One way to do this would be to bolster returnees’ predispositional characteristics prior to reentry. This can be achieved in part by enhancing students’ preparedness for the return by helping them to recognize personal change and encouraging mindful attention toward reentry. Preparedness can also be increased by introducing students to the concept of reentry shock. Reentry shock needs to be normalized as an accepted, anticipated, and transformative part of the sojourning experience. Another way to bolster reentry predisposition is to activate students’ adaptive personality traits by having them think about reentry as a cross-cultural experience and reminding them that they have already developed a skills repertoire for successful adaptation. Returnees may also be given a positive forecast for the long-term implications of identity development and intercultural personhood. Anticipatory coping skills can be further bolstered through enhancing returnees' perceptions of “fitting in” by connecting them with similar others and a supportive in-group. Finally, when possible, students can be encouraged to build transition time into their reentry plans to buffer some of the immediate experiences of reentry shock.

Upon return, the facilitation of psychological readjustment should take priority because of the significant strain on psychological health for returning sojourners (Martin \& Harrell, 2004). As demonstrated in these findings, access to a socially supportive and understanding interpersonal network is necessary for the return to psychological health. This can be partially fulfilled by encouraging returnees to establish and maintain ties with members of their host culture and co-sojourners through social media and social networking. Institutions can assist by developing and maintaining social media sites for returning students as well as facilitating organized opportunities for returnees to connect with international students and other study abroad returnees. Additionally, one of the biggest difficulties returnees face is in establishing meaningful communication with their close interpersonal network at home. Program facilitators 
can make efforts to reach out to family and friends of sojourners prior to reentry to prepare them for the types of difficulties returnees might experience and the kinds of support they may need.

Efforts to assist returnees to achieve functional fitness should follow, including realignment of social and behavioral skills such as communication competence. Cognitive communication competence might require only minor attention. For example, it might be wise to prepare students for the shock of returning to their home culture communication patterns, which may seem strange and/or abrasive to the returnee who likely developed a new rhythm of communication abroad (Hsu, 2010). More attention should be paid to affective communication competence to help students meet needs for meaningful self-expression and aesthetic coordination. This can be facilitated in part through fulfilling some of the psychological needs above, namely, connecting students to others who have had similar experiences and also equipping the returnees’ interpersonal network with knowledge about the communication difficulties and needs of the returning sojourner. Providing students with opportunities to talk with an interested audience about their experiences abroad could fulfill some affective communication needs. Operational communication competence is also important. Returnees would benefit from training on how to integrate aspects of their experiences abroad into their life at home and how to maximize personal and professional opportunities that might be available to them as a result of their experiences abroad. For example, reentry training could include instruction for how to feature international experiences on a resume or during a job interview.

This study opens some exciting avenues for continued research. One possibility is a closer look at critical turning points experienced by returnees in order to better identify benchmarks of reentry adaptation. One limitation of this study was that the 6-year gap in retrospective data collection made temporality difficult to establish. Benchmarks and phases of 
reentry adjustment would be easier to model with data collected at more frequent intervals. This would be beneficial for the development of reentry training programs. Continued development of a comprehensive communication-centered theory of sojourner adjustment that encompasses the entirety of the sojourn from pre-departure throughout reentry is also warranted. And, as the findings from this study indicate, contemporary sojourners make significant use of social media to develop and maintain the types of supportive communication networks necessary for different phases of their adjustment. A closer examination of the development of these networks and the types of messages used to support and maintain them would be fruitful.

Despite richness of findings, additional limitations must also be considered. Of primary importance, there is the potential for a selection effect. Although this sample represents varied reentry experiences, it is never-the-less a sample of students for whom reentry was significant enough to register as “an” experience. The voices of short-term sojourners who may have experienced a seamless or uneventful reentry are missing from these data. Also missing from the data are the experiences of the home network to which the sojourner returned. Including those voices would provide a fuller picture of the broader social and communicative environment to which the sojourner returns (see Chang, 2009). Similarly, returnees are apt to place a halo around their time abroad regardless of their actual experiences (Ryan \& Twibell, 2000). This tendency may have contributed to the overall positive glow participants cast over their study abroad as well as their penchant for waxing nostalgic about the sojourn. Although participants referred to their experiences abroad overwhelmingly positive (e.g., as a time of “wonder," that was “profound” and "incredible” in which "every day got better than the one before”), this does not mean that their actual lived experiences were so glowing. Data were further limited by a narrow demographic scope. A more heterogeneous sample would capture a wider range of reentry 
experiences especially for people of color and for people with identities they may choose to closet at home, but explore abroad. Additionally, although this sample represents only three study abroad destinations, the geo-cultural range (Western Europe, Asia, and South America) was an asset.

Guided by a grounded theory approach, this study applied Kim’s (2001) ITTCA as a sensitizing theoretical framework to begin theorizing about the full spectrum of sojourner adjustment including reentry. The resulting theoretical elaboration allows us to better understand student sojourners' reentry processes and consider ways to assist them in their re-integration and development of intercultural identity over time. Managing the process of reentry, often times for years beyond the return, is an important part of the cross-cultural experience that leads to fuller intercultural transformation. As seen in this study, it is not exclusively the sojourn that contributes to enhanced intercultural personhood. It is also the complexity of managing communication competence, personal and cultural identities, and interpersonal relationships upon return that result in the kinds of growthful experiences that foster intercultural personhood. 


\section{References}

Arthur, N. (2003). Preparing international students for the re-entry transition. Canadian Journal of Counselling, 37(3), 173-185.

Brabant, S., Palmer, C. E., \& Gramling, R. (1990). Returning home: An empirical investigation of cross-cultural re-entry. International Journal of Intercultural Relations, 14(4), 387404.

Butcher, A. (2002). A grief observed: Grief experiences of East Asian international students returning to their countries of origin. Journal of Studies in International Education, 6, 354-368. doi: 10.1177/102831502237641

Chang, Y. (2009). A qualitative study of temporary reentry from significant other's perspective. International Journal of Intercultural Relations, 33, 259-263. doi:10.1016/j.ijintrel.2009.02.002

Charmaz, K. (2002). Qualitative interviewing and grounded theory analysis. In J. F. Gubrium \& J. A. Holstein (Eds.), Handbook of interview research: Context and method (pp. 675694). Thousand Oaks, CA: Sage.

Charmaz, K. (2014). Constructing grounded theory (2nd ed.). Los Angeles, CA: Sage.

Cox, B. J. (2004). The role of communication, technology, and cultural identity in repatriation adjustment. International Journal of Intercultural Relations, 28, 201-219. doi:10.1016/j.ijintrel.2004.06.005

Glaser, B. (1978). Advances in the methodology of grounded theory: Theoretical sensitivity. Mill Valley, CA: The Sociology Press.

Gudykunst, W. B., \& Kim, Y. Y. (1997). Communicating with strangers: An approach to intercultural communication (3rd ed.). New York, NY: McGraw-Hill. 
Hsu, C.-F. (2010). Acculturation and communication traits: A study of cross-cultural adaptation among Chinese in America. Communication Monographs, 77, 414-425. doi: $10.1080 / 03637751.2010 .499367$

Institute of International Education (2014, November 17). Open Doors 2014: International students in the United States and study abroad by American students are at all-time high [Press Release]. Retrieved from: http://www.iie.org/en/Who-We-Are/News-andEvents/Press-Center/Press-Releases/2014/2014-11-17-Open-Doors-Data

Kartoshkina, Y. (2015). Bitter-sweet reentry after studying abroad. International Journal of Intercultural Relations, 44, 35-45. doi:10.1016/j.ijintrel.2014.11.001

Kim, Y. Y. (2001). Becoming intercultural: An integrative theory of communication and crosscultural adaptation. Thousand Oaks, CA: Sage.

Kim, Y. Y. (2005). Adapting to a new culture: An integrative communication theory. In W. B. Gudykunst (Ed.), Theorizing about intercultural communication (pp. 375-400). Thousand Oaks, CA: Sage.

Kim, Y. Y. (2008). Intercultural personhood: Globalization and a way of being. International Journal of Intercultural Relations, 32, 359-368. doi:10.1016/j.ijintrel.2008.04.005

Kim, Y. Y. (2012). Being in concert: An explication of synchrony in positive intercultural communication. In T. J. Socha \& M. J. Pitts (Eds.), The positive side of interpersonal communication (pp. 39-56). New York, NY: Peter Lang.

Lincoln, Y. S., \& Guba, E. G. (1985). Naturalistic inquiry. Beverly Hills, CA: Sage.

Martin, J. N. (1984). The intercultural reentry: Conceptualization and directions for future research. International Journal of Intercultural Relations, 8(2), 115-134. 
Martin, J. N. (1986a). Communication in the intercultural reentry: Student sojourners’ perceptions of change in reentry relationships. International Journal of Intercultural Relations, 10(1), 1-22.

Martin, J. N. (1986b). Patterns of communication in three types of reentry relationships: An exploratory study. Western Journal of Speech Communication, 50(2), 183-199.

Martin, J. N., \& Harrell, T. (2004). Intercultural reentry of students and professionals: Theory and practice. In D. Landis, J. M. Bennett, \& M. J. Bennett (Eds.), Handbook of intercultural training (pp. 309-337). Thousand Oaks, CA: Sage.

McKay-Semmler, K., \& Kim, Y. Y. (2014). Cross-cultural adaptation of Hispanic youth: A study of communication patterns, functional fitness, and psychological health. Communication Monographs, 81, 133-156. doi: 10.1080/03637751.2013.870346.

Morse, J. M. (1991). Strategies for sampling. In J. M. Morse (Ed.), Qualitative nursing research: A contemporary dialogue (pp. 127-145). Newbury Park, CA: Sage.

Onwumechili, C., Nwosu, P., Jackson, R. L., \& James-Hughes, J. (2003). In the deep valley with mountains to climb: Exploring identity and multiple reacculturation. International Journal of Intercultural Relations, 27(1), 41-62.

Pitts, M. J. (2009). Identity and the role of expectations, stress, and talk in short-term sojourner adjustment: An application of the integrative theory of communication and cross-cultural adaptation. International Journal of Intercultural Relations, 33, 450-462. doi:10.1016/j.ijintrel.2009.07.002

Pitts, M. J., \& Miller-Day, M. (2007). Upward turning points and positive rapport development across time in researcher-participant relationships. Qualitative Research, 7, 177-201. doi: $10.1177 / 1468794107071409$ 
Pritchard, R. (2011). Re-entry trauma: Asian re-integration after study in the West. Journal of Studies in International Education, 15, 93-111. doi: 10.1177/1028315310365541

Rohrlich, B. F., \& Martin, J. N. (1991). Host country and reentry adjustment of student sojourners. International Journal of Intercultural Relations, 15(2), 163-182.

Rubin, H. J., \& Rubin, I. S. (1995). Qualitative interviewing: The art of hearing data. Thousand Oaks, CA: Sage.

Ryan, M. E., \& Twibell, R. S. (2000). Concerns, values, stress, coping, health and educational outcomes of college students who studied abroad. International Journal of Intercultural Relations, 24(4), 409-435.

Smith, S. (1998). Identity and intercultural communication competence in reentry. In J. N. Martin, T. N. Nakayama, \& L. A. Flores (Eds.), Readings in cultural contexts (pp.304314). Mountain View, CA: Mayfield.

Strauss, A., \& Corbin, J. (1998). Basics of qualitative research: Techniques and procedures for developing grounded theory (2nd ed.). Thousand Oaks, CA: Sage.

Szkudlarek, B. (2010). Reentry - a review of the literature. International Journal of Intercultural Relations, 34, 1-21. doi:10.1016/j.ijintrel.2009.06.006

Uehara, A. (1986). The nature of American student reentry adjustment and perceptions of the sojourn experience. International Journal of Intercultural Relations, 10(4), 415-436.

Walling, S. M., Eriksson, C. B., Meese, K. J., Ciovica, A., Gorton, D., \& Foy, D. W. (2006). Cultural identity and reentry in short-term student missionaries. Journal of Psychology and Theology, 34(2), 153-164.

\footnotetext{
${ }^{i}$ I reference "a grounded theory approach" in recognition of on-going scholarly debate about what counts as a "true" grounded theory (Charmaz, 2014). I followed data collection and data analytic procedures established by grounded theorists to generate in-depth experiential data and probe those data for theoretical richness and connections. I used
} 
an emergent design, but also engaged in a constant comparative practice between emergent codes and ITCCA domains as sensitizing constructs. 